\title{
Symbolic Representation for Introduction of Concept of Decimal System in Mexican School Children
}

\author{
Solovieva $\mathrm{Y}^{1}$, Rosas Rivera $\mathrm{Y}^{1}$, Quintanar L $\mathrm{L}^{1}$ \& García M. A ${ }^{1}$ \\ ${ }^{1}$ Master in Neuropsychological Diagnosis and Rehabilitation, Faculty of Psychology, Autonomous University of \\ Puebla, Puebla, México \\ Correspondence: Solovieva Y., Master in Neuropsychological Diagnosis and Rehabilitation, Faculty of \\ Psychology, Autonomous University of Puebla, Puebla, México. E-mail: yulia.solovieva@correo.buap.mx
}

Received: September 3, 2013

Accepted: September 20, 2013 Online Published: September 28, 2013

doi:10.5539/ies.v6n10p102

URL: http://dx.doi.org/10.5539/ies.v6n10p102

\begin{abstract}
The present study describes the usage of strategies of symbolic representation during teaching introduction of decimal system in primary school in Mexico. Our research is based on Activity Theory conception of teaching-learning process and of gradual introduction of scientific concepts in school age. The method includes symbolic external representation of mathematic, logic and spatial relations. Children from the second grade of primary school took part in the study. The children were included in joined actions with constant orientation of the teacher. Specific Program was designed for introduction of decimal system and applied during 6 month 3 times per weak. The results showed that children acquired significant symbolic abilities necessary for understanding the concept of decimal system. We consider that proposed method could be a new approximation for solution of common difficulties which arise at primary school during initial teaching of mathematics.
\end{abstract}

Keywords: symbolic representation, school age, teaching of decimal system, activity theory

\section{Introduction}

At primary school, the way mathematics is thought is a matter of great importance. In Mexico, as in many other countries, the level of children's knowledge in this area is very low (SEP, 2011). This means that pupils of third grade of primary school can only solve exercises with low degree of difficulty (elementary operations, increasing sequence with an additive constant, to identify the predecessor of a number, etc.). The teaching method proposed by Secretariat of Public Education (2011) emphasizes that the teacher's task is to create learning environments in order to make pupils think about the methods that perform, promote communication of mathematical ideas that arise during class and evaluate the level of skills that students develop. Nevertheless, no conceptual knowledge is included in current methodology for mathematics. Symbolic preparation is not considered as important aspect of knowledge and learning. The actual school methods are based on traditional repetition and memorization of examples with no kind of symbolic or logic structure of concepts of number and decimal system.

The introduction of decimal system represents one of the essential aspects of learning at primary school. This is the theme what occupies most of the activities in the first three years of primary school education (Ruesga y Guimaraes, 2011). The decimal system is considered a positional system, because the digits are not independent but are subject to their spatial position. No digit has absolute meaning, but depends on spatial specific position (Silva y Barela, 2010; Ávila y García, 2008; Luria, 1995). The problem is that such knowledge is not explicit and apparently children have to "discover" it. Normally, children learn to sum and rest and to fulfill multiple operations, but they do not receive any orientation or explanation of the way to "discovery" of logic and theoretical basis of decimal system.

There is no doubt that decimal system is a symbolic system based on relative meaning of each digit. Each new column of the decimal number system is considered as a new measure count, which is 10 times greater than the extent of the previous column, for example, 10 units of the first column (units) given unit of the second column (tens). Left or right position has also specific meaning in decimal system. The reflection of such relationships could allow students show arithmetic actions, laws and combination translational. It is also possible to emphasize that counting by equal units (not necessary by 10 units), allows preparation of the conceptual introduction of any numeric system (not only decimal system) (Talizina, 2009, Salmina, 2001). The pertinent question could be how to manage an appropriate way of introduction of such knowledge at school? 
It is possible to find an answer on not traditional way of education proposed on the basis of Activity Theory (Talizina, Solovieva and Quintanar, 2010; Solovieva and Quintanar; 2010; Galperin, 2009; Talizina, 2009; Salmina, 2001). This general psychological theory applied to the process of teaching and learning shows how it is possible to reorganize and systematize academic programs in order to guarantee favorable way of assimilation and generalization of any knowledge. Between the main aspects of such methodology we can mention: 1) constant and orientation in formation of theoretical concepts and 2) symbolic external representation of phenomenon or process which should be learned.

In case of introduction of decimal system in primary school it is necessary to remember basic essential components relevant for number concept formation in general Specifically, mathematic content is organized around four components: logical, symbolic, mathematical and spatial which were detected in some previous psychological studies within activity theory (Salmina y Filomonova, 2002; Solovieva, Ortiz y Quintanar, 2010; Solovieva, Quintanar \& Ortiz, 2012).

The objective of this study consisted in showing pedagogical experience of usage of symbolic representation for introduction of decimal concept in primary school in Mexico.

\section{Method}

\subsection{Participants}

Children from second grade of elementary school were included in formative experiment. The average age was 7.25 years. All children assisted small private primary school in the city of Puebla and had no pathological history in their development.

\subsection{Pedagogical Experiment and Applied Program}

The Program for introduction of decimal system was created and was applied 3 days per week during 6 months. The implementation of the program could be called as "formative pedagogical experiment" (Talizina, 1998; Salmina, 2001, Talizina, Solovieva y Quintanar, 2010). In such studies the method consists of gradual formation of concepts, skills or actions starting from level " 0 ", that is, providing gradual cooperation within the zone of proximate development, according to L.S. Vigotsky's conception. The introduction of decimal system was organized and guided by an adult who knows the operative structure and all kinds of necessary orientation what can guarantee reflective and conscious acquisition of proposed concepts.

The Program was applied as common sessions at school and presented as joint collective activity divided between adults and children. The work was organized in groups and in pairs of children. The program included specific tasks for symbolic, logical, numeric and spatial components necessary for introduction of decimal system. Specific kinds of external symbolic representations were used during the whole process. The table 1 represents the general content of the program divided into 4 steps according to actions, orientation, means of symbolization and materials. The orientation with symbolic means is always presented by teacher, while the pupils can propose the materials for all the actions.

Table 1. The content of the program

\begin{tabular}{|c|c|c|c|}
\hline Actions & Orientation & Means of symbolization & Materials \\
\hline $\begin{array}{l}\text { 1. Measure of } \\
\text { highness, } \\
\text { broadness, volume, } \\
\text { longitude, etc. }\end{array}$ & $\begin{array}{l}\text { What shall we measure? We shall } \\
\text { call it " } M \text { ". } \\
\text { With what shall we measure? We } \\
\text { shall call it " } m \text { ". } \\
\text { How many times shall be apply or } \\
\text { mean ("m") to complete with the } \\
\text { measuring ("v")? }\end{array}$ & $\begin{array}{l}\text { The card with symbols: M, } \\
\mathrm{m}, \mathrm{v} \\
\text { Means for measure (pens, } \\
\text { glasses, pencils, lines, } \\
\text { pieces of paper and so on). }\end{array}$ & $\begin{array}{l}\text { Furniture, } \\
\text { liquids, objects, } \\
\text { toys, lines on the } \\
\text { floor, windows, } \\
\text { doors and so on. }\end{array}$ \\
\hline $\begin{array}{l}\text { 2. Comparison of } \\
\text { magnitudes which } \\
\text { were measured } \\
\text { with same mean }\end{array}$ & $\begin{array}{l}\text { Can we compare what we measure } \\
\text { with the same mean? } \\
\text { The less is the size of the mean, the } \\
\text { more the quantity of times to apply } \\
\text { the mean. } \\
\text { The bigger is the mean, the less is } \\
\text { the quantity of times to apply the } \\
\text { mean. }\end{array}$ & $\begin{array}{l}\text { Symbols: equal }(=) \text {, more } \\
(>) \text {, less }(<)\end{array}$ & Same \\
\hline
\end{tabular}


It is not possible to compare if we

do not use the same mean.

3. Introduction of unit

4. Elaboration of decimal system
We can call the mean we chose "the unit" for measure.

Each next unite can be 10 times bigger (smaller) then the previous one. Each next (on the right side) unit includes 10 previous units.

$\begin{array}{ll}\begin{array}{l}\text { Schemes and tables for } \\ \text { representation of decimal } \\ \text { system. }\end{array} & \begin{array}{l}\text { Matchers and } \\ \text { boxes for } \\ \text { organization and } \\ \text { Symbols for representation } \\ \text { of units. }\end{array} \\ \begin{array}{l}\text { representation of } \\ \text { letchers for "right" and } \\ \text { "left" orientation inside } \\ \text { decimal system }\end{array} \\ \end{array}$

\subsection{Pedagogical Procedure}

The usage of the program with the means of symbolization is illustrated by some concrete examples.

Actions of Measure. Measurements were performed considering various objects and magnitudes. Specific terms like "Magnitude", "Measure" and "Number" as "times or quantity of measuring" were introduced and explained to children form the very beginning. External symbolization of each term was used. The figure 1 shows the symbolization and orientation card for this task. The card includes specific questions which help the child to understand specific mathematic sense of the task. When we need to measure anything (an object or parameter of an object) we have to chose a mean (symbol) with which we can measure. In this case, "Number" corresponds to the quantity of times a measurement is used and not only to specific digit. These elements are described on the symbolic card "Measure". During each concrete task children had to use this specific symbolic cards. Firstly, they chose an object and a feature of an object to measure (e.g. a highness or broadness of a toy, window, board, distance between two places in the classroom or between tow children, water bottles) and something with which we can to measure such objects (pencils, chalks, paper strips, glasses and so on). The measurement of volumes of different liquids with the help of specific measures was used as well. Subsequently, the gathered data was written down on the students notebooks using symbolic "Measurement Scheme".

\begin{tabular}{|c|}
\hline $\begin{array}{l}\text { Magnitude }(\mathrm{M})=\text { object or parameter which we wand to measure } \\
\text { (What do we want to measure?) }\end{array}$ \\
\hline $\begin{array}{c}\text { Measurement }(\mathrm{m})=\text { symbol or mean we chose as a measure } \\
\text { (What do we measure with?) }\end{array}$ \\
\hline $\begin{array}{l}\text { Quantity of time }(\mathrm{v})=\text { Quantity of times we use the measure } \\
\qquad \text { (How many times do we measure with this mean?) }\end{array}$ \\
\hline
\end{tabular}

Figure 1. Symbolic measurement card

The Figure 2 shows an example of a task of the materialized stage, in which a drawn path is measured using a paper foot. During the work the teacher explained the meaning of the card and of each symbolic mean. Afterwards, children had to act according to the card answering together all the questions. Same procedure was applied to multiple situations, various objects and parameters of objects. Children always took part in selections and creation of tasks. 


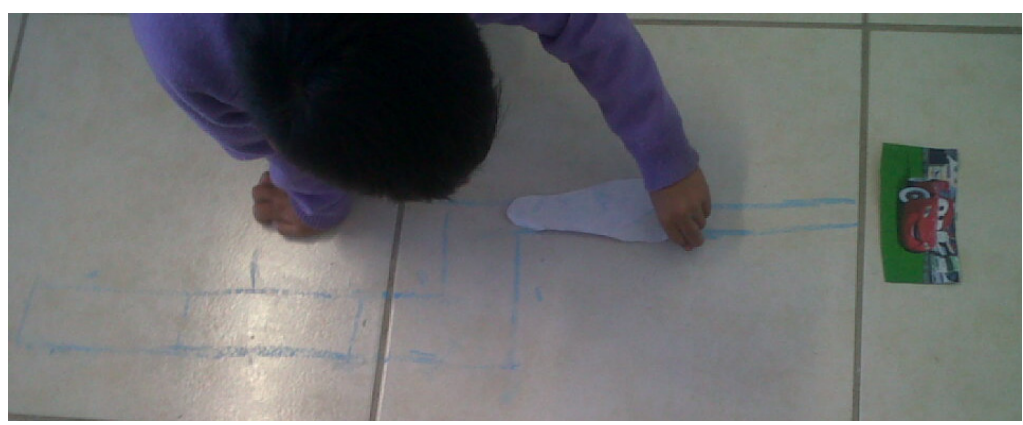

Figure 2. Example tasks measuring action, $M=$ car track; $m=$ paper stand; $v=7$ times

Actions of comparison and introduction of unit.

In this stage, every task was performed using a common measurement to compare different objects and liquids, which can be measured. In this case, external mean (symbol) to make the measurement was proposed by a teacher to all the participants: the same ribbon. The goal of such procedure was to teach children that the smaller was the size of the mean, the more times they would have to use it to measure one object. And the other way around, the bigger is the mean, the lesser times they would have to use it is measuring the same object (parameter). In such way of teaching the mean (external symbol) can be gradually reflected as a unit to provide correct measuring.

The Figure 3 shows how the children measured distances ("Magnitudes") between various objects or places. In some exercises children had to find out which roads where longer or shorter. They had to use same mean in such tasks. For instance, matches were used as means for measure. All data was recorded on the board and a comparison was made between the paths and lines in all occasions. The children used mathematical symbols "less than" $(<)$, "greater than" $(>)$ and "equal" $(=)$ to understand the relationships between the magnitudes worked. For each answer they chose the appropriate symbol with the help of the adult. Our goal was to obtain reflection about the following condition: if we want to compare objects or parameters, we have to use same mean. On the contrary, if we use different means, we can not compare results of measuring.

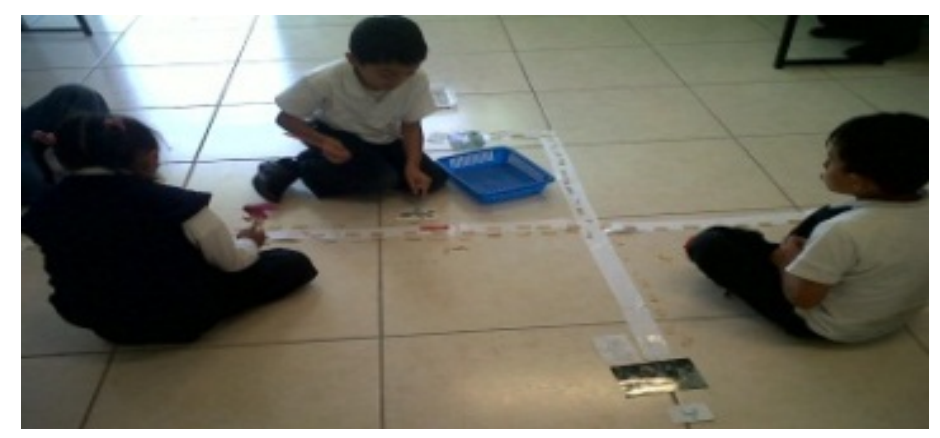

Figure 3. Example of a distance-measuring task

The Figure 4 shows an example of exercise of comparison of paths drawn on paper or on board. Afterwards, the pupils wrote down the data obtained in a registry sheet. It was necessary to identify the mean used for measurement, to show the shortest path, the longest path and their numeric representation. Children were constantly asked by the teacher about all the steps of the work with the emphasis of interrelation of 3 variables: $\mathrm{M}, \mathrm{m}, \mathrm{v}$. 

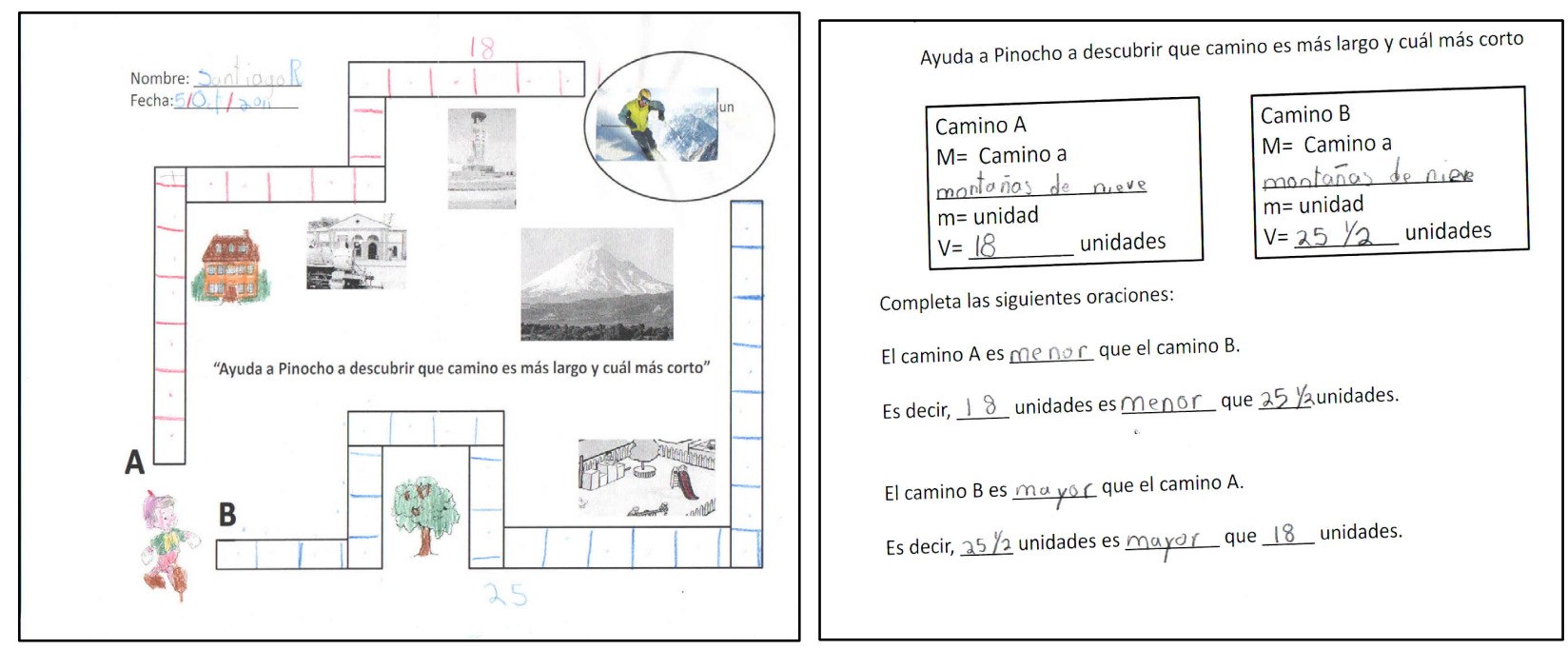

Help Pinocchio to find that path which is longer and shorter

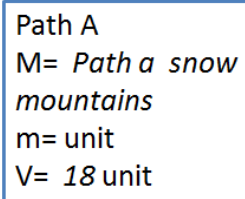

Complete the following sentences:

The path $\underline{A}$ is shorter than path $\underline{B}$.

Is mean, $\underline{18}$ unit is shoter than $\underline{251 / 2}$ unit.

The path $\underline{B}$ is longer than path $\underline{A}$.

Is mean, $25 \frac{1}{2}$ unit is longer than $\underline{18}$ unit.

Figure 4. Exercise for comparison of objects

Path $\mathrm{B}$
$\mathrm{M}=$ Path a snow
mountains
$\mathrm{m}=$ unit
$\mathrm{V}=25 \mathrm{r} / 2$ unit

$V=25 \frac{1}{2}$ unit 

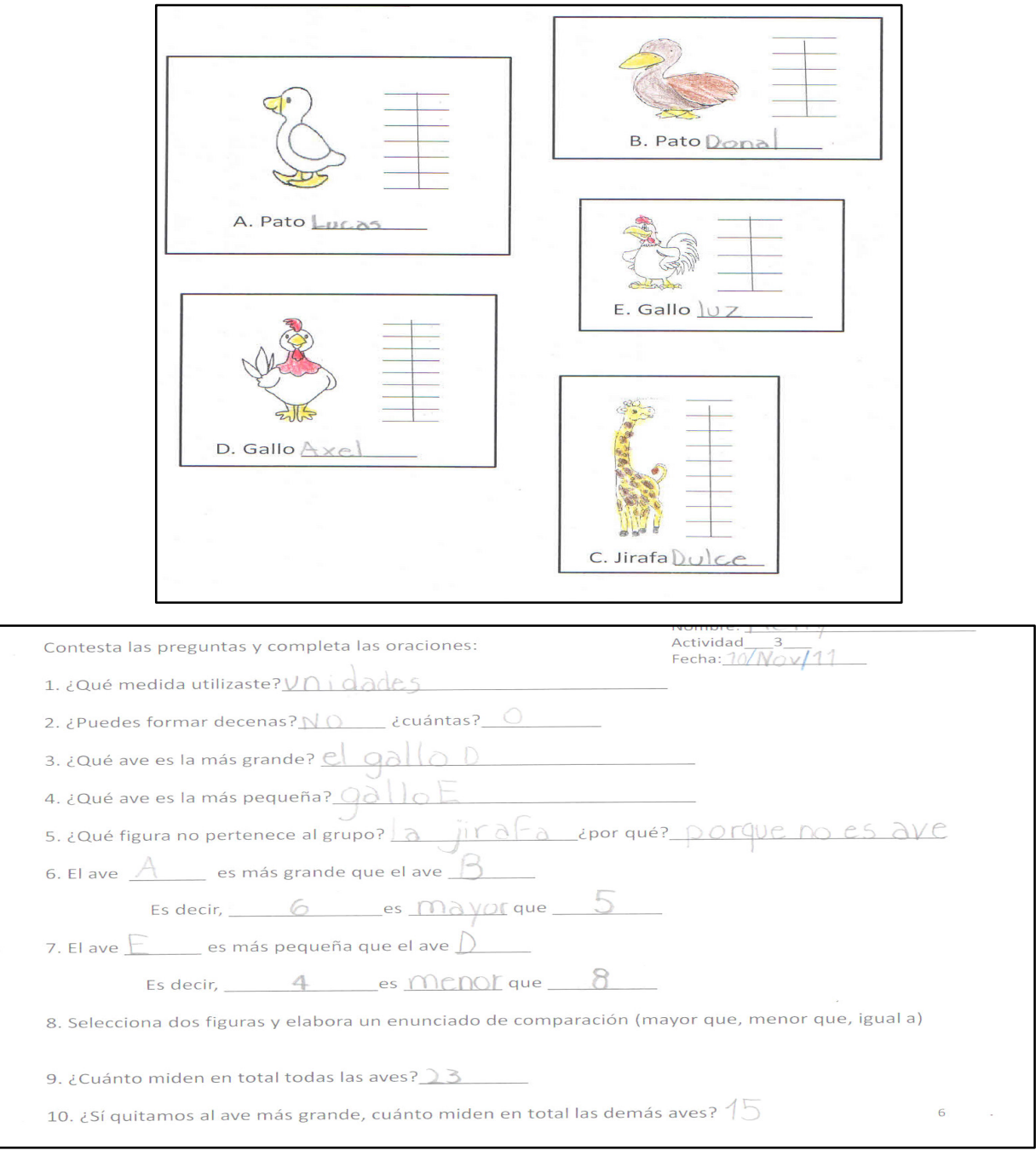

Answer the questions and complete the sentences:

1. What measure did you use? units

2. You can form tens? No _ ¿ chow many? 0

3. What is the largest bird? the rooster $D$

4. What is the smallest bird?_ the rooster $E$

5. Which figure outside the group? ___ giraffe__why? _ because there is not a bird

6. The bird__ $A$ __ is more largets than the bird _

Is mean, 6 units__ is _ largets___ than __ 5 units

7. The bird__ E $E$ is more smallest than the bird

Is mean, 4 units__ is smallest___ than _ 8 units

8. Select two figures and produced a statement of comparison (greater than, less than, equal to)

9. What is the sum of all the birds?___ 23 units

10. If you take away the largest bird, What is the sum of all the birds? 15 units

Figure 5. Exercise of a measurement comparison task 
The same kind of work was applied to the measure of liquids using different units.

Elaboration of decimal system.

In this step, the external model for representation of decimal system was used. Children were explained that it is possible to use units in such way that each next unit can be 10 times bigger then the previous one. Such unit is called "ten". The Figure 6 shows an example of elaboration of a symbolic external scheme for representation of grades within decimal system. When we count and get ten o more units, we can "pass" to the next unit on the right side of the scheme.

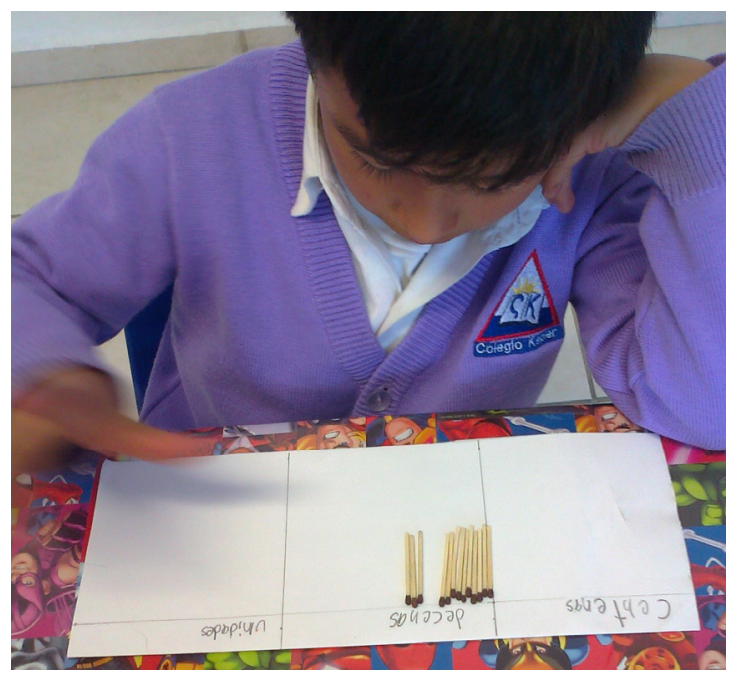

Figure 6. Representation of units and tens with external scheme

Afterwards, children worked with matches using a ribbon to tie them up in groups. Each group included 10 matches and was called as next unit or unit of ten. Same procedure was used to represent units for hundreds and thousands. In this case it was enough to use symbolic representation without usage of concrete matches. Children had to understand an idea that each following unit is 10 times bigger. The figure 7 shows an example of tens constructions and their symbolic localization on the positional value table.

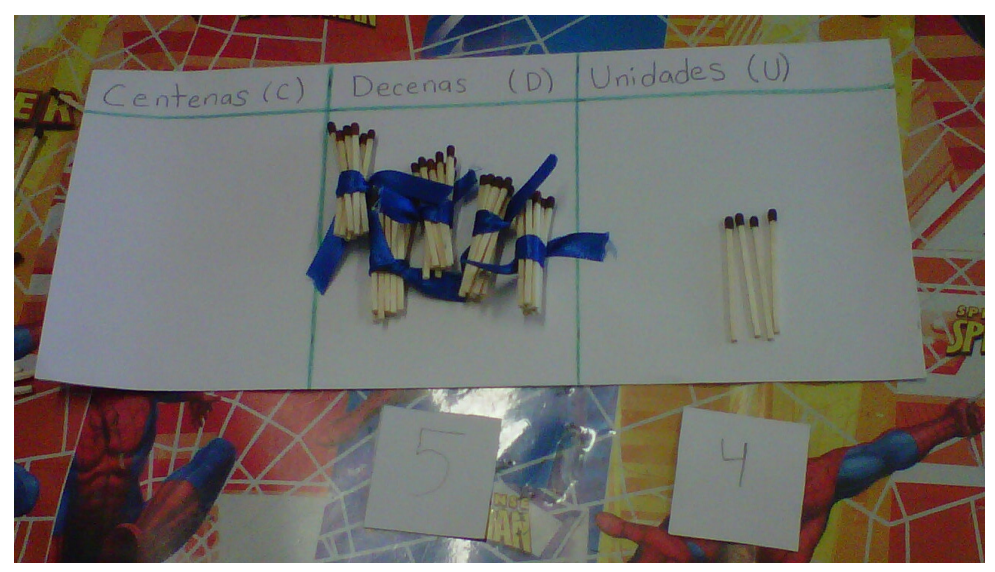

Figure 7. Tens construction and there numerical representation

Finally, the children learned to represent different number and quantities using symbolic scheme for decimal system. In all tasks children had to identify of the biggest and the smallest unit and differential the concept of "digit" and the concept of "positional unit" (figure 8). 


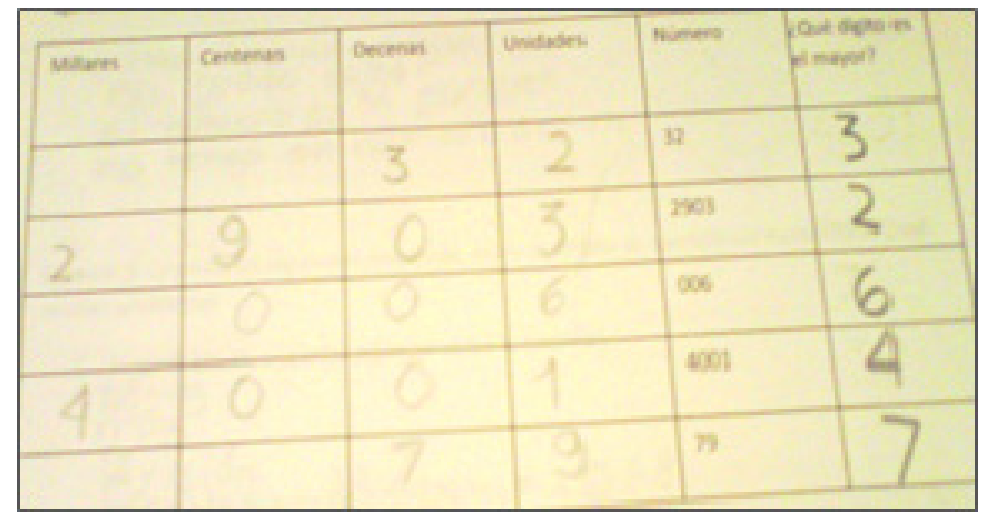

Figure 8. Symbolic representation of decimal system

Final test. At the beginning and at the end of pedagogical process children were asked some question which can show the level of reflection concerning the concept of decimal system and positional units. The table 2 presents the answers of children before and after the teaching experiment.

Table 2. Initial and final answers

\begin{tabular}{|c|c|c|}
\hline Task & Initial test & Final test \\
\hline $\begin{array}{l}\text { What one is bigger: } 3 \mathrm{~cm} \text { or } 1 \\
\mathrm{~m} \text { ? }\end{array}$ & 3 , because 3 is bigger than one. & $\begin{array}{l}1 \text { meter is bigger than } 3 \\
\text { centimeters because } 1 \text { meter } \\
\text { includes } 100 \text { centimeters }\end{array}$ \\
\hline $\begin{array}{l}\text { What one is bigger: } 5 \text { liters or } \\
2 \text { kilograms? }\end{array}$ & 5 is bigger than 2 . & $\begin{array}{l}\text { Is not possible, different means } \\
\text { were used for measurements }\end{array}$ \\
\hline $\begin{array}{l}\text { What is bigger: two quarters of } \\
\text { hour or a half hour? }\end{array}$ & $\begin{array}{l}\text { I don't know, I haven't been } \\
\text { taught to read the clock. }\end{array}$ & $\begin{array}{l}\text { They are equal because one } \\
\text { quarter plus one quarter means } \\
\text { half hour }\end{array}$ \\
\hline
\end{tabular}

It is possible to notice the qualitative difference between the level of reflection and theoretical comprehension of mathematic relations before and after working according to our program. The final assessment has shown that the children were able to identify the positional value of digits in a number, to write the numbers correctly, to compare measures correctly, to perform arithmetic operations and to understand relationships in the decimal numeric system. All children were able to use symbolic representation of all essential relations within decimal system.

\section{Discusion and Conclusions}

According our data, the teaching should be understood as directed and organized process (Talizina, Solovieva and Quintanar, 2010) and not as empiric configuration of various operations and actions. The teacher should clearly understand what is he/she teaching and how the best result could be achieved. Such organization of teaching process allows the children to be conscious of their learning (Talizina, 2009) allows and guarantees the development of mathematical skills in our children.

Such way of teaching is opposite to the constructivist methods of working just with separate individual actions of children with no specific purpose established and putting more emphasis on the teaching of symbols just as any other external object in front of the child (Martin, 2003; Castaño, 2008). The techniques used in constructivist approach never retake the measurement action properly. Such methods pretend to measure only empirically without any objective and with no relation to the concept of decimal system. In traditional school children can never understand any relation between unit of measurement and number concept. They measure everything but the do not know what for do they measure. The measurement is presented as a kind of "free individual" process 
for independent "construction" of the knowledge by each child without any orientation. Some studies show that the only strategy used by children in traditional primary school in Mexico during solution of exercises is counting by fingers, personal drawings and mental calculations (Buto y Gómez, 2011; García, 2011). Such approach is very common and dominants the system of teaching of mathematic abilities in may countries.

By this research we wanted to show how the work could be done during introduction of decimal system. Only correct election and organization of appropriate actions may conduct to positive result in teaching. In this very case such actions are related to measurement of features of objects (e.g. highness, broadness and volume). But we stress that not only election of actions is necessary. Constant orientation with the help of symbolic means and specific questions with constant participation of an adult are essential part of our methodology. Only such kind of organization of learning process permits to guarantee successful assimilation and generalization of the concept of decimal number system (Dadidov, 1988; Salmina, 2010). The purpose of each activity and of each task is explained and oriented by a teacher. After such training, there were no errors in reading of new numbers displayed for the children as some researchers have found as constant negative feature of children at primary school in different countries (Butto y Gómez, 2011; García, 2011; Gómez, 1991).

The principles of innovational way of teaching according to activity theory methodology open new perspectives for educational process. It is possible to create original systems of strategies that ensure the understanding of decimal system in its symbolic essence. We hope to continue our research towards generalization of pedagogical experience and possibility of introduction of new strategies of symbolic representation in formation of mathematic concepts.

\section{References}

Ávila, A., \& García, S. (2008). Los decimales: más que una escritura. México: INEE.

Block, D., \& Solares, D. (2001). Las fracciones y división en la escuela primaria: análisis didáctico de un vínculo. Educación matemática, 13(2).

Butto, C., \& Gómez, L. M. (2011). Las representaciones del sistema numérico decimal indo-arábigo en niños de primer grado de primaria. XIX Congreso Mexicano de Psicología. Cancún Center, Cancún, Quintana Roo, México.

Castaño, J. (2008). Una aproximación al proceso de comprensión de los numerales por parte de los niños: Relaciones entre representaciones mentales y semióticas. Univ. Psichol., 895-907.

Davídov, V. (1988). La enseñanza escolar y el desarrollo psíquico. Moscú: Progreso.

Galperin, P. Ya. (2009). La formación de los conceptos y de las acciones mentales. In Quintanar, L. Y., \& Solovieva, Y. (Eds.) (Comps.), Las funciones psicológicas en el desarrollo del niño. México: Trillas.

García, O. (2011). Las matemáticas naturales del niño y su transición a la educación formal en la escuela formal. XIX Congreso Mexicano de Psicología. Cancún Center, Cancún, Quintana Roo, México.

Gómez, C. (1991). Cognición, contexto y enseñanza de las matemáticas. Comunicación, lenguaje y educación, $11,11-26$.

Martín, A. (2003). Operación aritmética: la división. Boletín: Las matemáticas en secundaria, 25.

OCDE. (2012). Perspectivas México: Reformas para el cambio. México: OCDE.

Ruesga y Guimaraes. (2011). Sistema de numeración decimal: Un instrumento para seleccionar libros de texto de los tres primeros años de enseñanza. Indicações para os trabalhos da, 13, 1-12.

Salmina, N., \& Filiminova, O. (2010). Problemas en el aprendizaje de las matemáticas básicas y su corrección. Puebla: Instituto universitario de estudios avanzados.

Salmina, N. (2001). La enseñanza de las matemáticas en la escuela primaria. In Talizina, N. (Ed.), La formación de las habilidades del pensamiento matemático. México: Universidad Autónoma de San Luis Potosí.

SEP (2011). Evaluación Nacional de Logro Academico en Centros Escolares. ENLACE. México: SEP.

Silva, A., \& Barela, C. (2010). Los materiales concretos en la enseñanza de la numeración. Quehacer educativo, 26-33.

Solovieva Y., Quintanar L., \& Ortiz, G. (2012). The Formation of Initial Components of Number Concepts in Mexican Children. Psychology Research, 2(7), 422-430.

Solovieva, Y., Ortiz, G., \& Quintanar, L. (2010). Formación de conceptos numéricos iniciales en una población de niños mexicanos. Cultura y educación, 20(2). http://dx.doi.org/10.1174/113564010804932157 
Solovieva, Y., \& Quintanar, L. (2010). El desarrollo del niño y los métodos de enseñanza. Elementos, 77, 9-13.

Talizina, N. (2009). La teoría de la actividad aplicada a la enseñanza. México: BUAP.

Talizina, N., Solovieva, Y., \& Quintanar, L. (2010). La aproximación de la actividad en psicología y su relación con el enfoque histórico-cultural de L. S. Vygotsky. Novedades educativas, 230, 4-8.

\section{Copyrights}

Copyright for this article is retained by the author(s), with first publication rights granted to the journal.

This is an open-access article distributed under the terms and conditions of the Creative Commons Attribution license (http://creativecommons.org/licenses/by/3.0/). 